\title{
Apresentação Educação do Campo
}

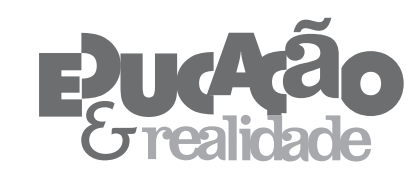

Claudia Glavam Duarte Simone Valdete dos Santos

'Universidade Federal do Rio Grande do Sul (UFRGS), Porto Alegre/RS - Brasil

A luta por acesso à escola de qualidade no meio rural, no campo brasileiro, vem adquirindo visibilidade e força nos últimos anos. O que hoje nomeamos por Educação no/do Campo tem sua trajetória vinculada aos movimentos sociais que, na década de 90 do século passado, exigiam uma Educação a qual legitimasse os modos de vida dos sujeitos pertencentes ao campo.

Especificamente, o nascedouro da luta pela constituição dessa Educação do Campo no Brasil está vinculado ao manifesto construído por educadores e educadoras que participaram do "I Encontro Nacional de Educadoras e Educadores da Reforma Agrária” (I ENERA), realizado em julho de 1997, na Universidade de Brasília (UnB). Este evento sistematizou grande parte dos anseios educacionais dos povos vinculados ao campo e, ao mesmo tempo, divulgou às produtivas experiências educacionais realizadas pelo Movimento dos Trabalhadores Rurais Sem Terra (MST), o qual fora premiado em 1995 pelo Fundo das Nações Unidas para a Infância (UNICEF) por suas práticas educativas de distinção, responsáveis pela efetivação de uma escola de qualidade no meio rural.

Educação \& Realidade, Porto Alegre, v. 40, n. 3, p. 659-666, jul./set. 2015. 659 http://dx.doi.org/10.1590/2175-623656800 
As primeiras experiências educativas nacionais, tributárias às proposições do Manifesto e do documento base produzidos pelo I ENERA, financiadas pelo Governo Federal, ocorreram por meio da Portaria no 10/1998, do então Ministério Extraordinário de Política Fundiária, na instituição do Programa Nacional de Educação na Reforma Agrária (PRONERA), cujas ações se concentraram, sobretudo, na alfabetização de adultos e na formação de professores em licenciaturas inovadoras, promotoras da Pedagogia da Alternância, a qual corresponde ao privilégio de tempos diferenciados dentro do currículo, garantindo aos estudantes experiências educativas na instituição educacional (tempo escola / tempo universidade), no reconhecimento e monitoramento de experiências educativas vivenciadas pelos estudantes em suas comunidades rurais (tempo comunidade).

O PRONERA se constituiu, desde os anos 1990, em um importante programa da Educação do Campo, acumulando experiências em licenciaturas específicas nas diversas universidades públicas e comunitárias $^{1}$ protagonistas de propostas pedagógicas, às quais podemos nomear como inéditos viáveis na perspectiva do pensamento de Paulo Freire, com a participação dos movimentos sociais do campo.

Importante salientar que as reivindicações presentes no I ENERA se opunham de forma categórica do que até então se nomeava por educação rural que defendia, segundo Adonia Antunes Prado (1995), dois objetivos para a escola rural: a valorização do homem rural em função do meio em que vive e sua fixação e adaptação no campo, a fim de formar mão de obra especializada em seu meio.

De forma divergente, as propostas que ali nasciam buscavam romper com o ruralismo pedagógico que, desde a década de 40, insistia em fixar o homem no campo, a fim de apaziguar a relação ameaçadora que se estabelecia, na época, entre a cidade e o campo, ocasionada pelo êxodo rural. Poderíamos afirmar que o discurso de permanência do homem do campo no campo esteve durante certo tempo alicerçado no "medo ambiente" (Bauman, 1998, p. 33), ou seja, no clima de insegurança causado pela crescente invasão da área urbana pelo homem proveniente do meio rural.

A Conferência Nacional: Por uma Educação Básica do Campo, ocorrida em 1998 em Luziânia - Goiás, promovida pela Organização das Nações Unidas (UNICEF), MST, Universidade de Brasília e Conferência Nacional dos Bispos do Brasil (CNBB), na continuidade do I ENERA, propõe a inclusão das comunidades rurais, a construção de um projeto de desenvolvimento do campo promovido também pelas escolas.

É nesta nova perspectiva que se defenderá e se enfatizará uma escola no/do Campo. Caldart (2005, p. 27) afirma que "No: o povo tem direito a ser educado no lugar onde vive. Do: o povo tem direito a uma educação pensada desde o seu lugar e com sua participação, vinculada a sua cultura, e suas necessidades humanas e sociais".

660 Educação \& Realidade, Porto Alegre, v. 40, n. 3, p. 659-666, jul./set. 2015. 
No âmbito das instituições federais de Ensino Superior, em 2007, ocorreu a promoção de Licenciaturas em Educação do Campo, em caráter experimental, considerando a possibilidade de editais específicos, por intermédio de quatro universidades: Universidade Federal de Brasília (UNB), Universidade Federal da Bahia (UFBA), Universidade Federal de Minas Gerais (UFMG) e Universidade Federal de Sergipe (UFS).

Posterior ao desenvolvimento destes projetos iniciais, diante da experiência acumulada nas instituições de Ensino Superior e nos movimentos sociais do campo, houve o lançamento em 2012 do Programa Nacional de Educação no Campo (PRONACAMPO). Programa robusto, em termos de ações governamentais e investimento de recursos públicos, o qual está desenvolvido, conforme seu documento base ${ }^{2}$, em quatro eixos: Gestão e Práticas Pedagógicas; Formação Inicial e Continuada de Professores; Educação de Jovens e Adultos e Educação Profissional; Infraestrutura Física e Tecnológica.

$\mathrm{Na}$ formação inicial e continuada de professores destacamos o edital Secretaria de Educação Superior/Secretaria de Educação Profissional e Tecnológica/Secretaria de Educação Continuada, Alfabetização, Diversidade e Inclusão 02/2012 PROCAMPO, o qual está patrocinando turmas de licenciaturas nos 27 Estados $^{3}$ do país, nas áreas de Ciências da Natureza, Linguagens, Ciências Agrárias e Matemática.

Neste novo cenário, de investimento de recursos públicos nas escolas do campo, considerando sua especificidade, é emergente a reflexão teórico-metodológica das experiências, das perspectivas da Educação do Campo, tanto no Brasil, por intelectuais brasileiros, quanto análises externas, internacionais.

Comecemos por nos perguntar por que esta escola se diferencia das outras? O que ela pressupõe que a categoriza de maneira diferente? Teríamos nessas especificidades alguma potência para pensar a educação em geral? É neste sentido que a reflexão proposta por Pilar Abós Olivares, da Universidade de Zaragoza, Espanha questiona: El modelo de Escuela Rural ¿Es un Modelo Transferible a Otro Tipo de Escuela? A reflexão proposta pela autora é oriunda de uma pesquisa que envolveu instituições espanholas e latino-americanas, a qual buscou compreender as especificidades da escola rural e as possíveis articulações com as escolas de modo geral. Segundo a autora, algumas características presentes na escola rural podem ser pensadas como balizadoras para a construção de uma educação que defenda valores de justiça e solidariedade. Assim, os pressupostos de inclusão através do desenvolvimento de práticas pedagógicas heterogêneas, a busca por uma sociedade mais justa, o respeito pela cultura local e a superação do individualismo, são características que deveriam alicerçar não só a escola rural, mas toda a educação.

No entanto, o desprestígio enfrentado pela escola rural acaba por impedi-la de assumir um protagonismo nas questões educacionais. 
Nesta perspectiva, a pesquisadora aponta para a urgência de darmos visibilidade as práticas que tem sido desenvolvidas no meio rural, pois somente com argumentos rigorosos é que esta poderá se constituir em uma potência para pensarmos sobre a educação, ou seja, será somente através do conhecimento rigoroso das características das escolas rurais, tais como a atenção à diversidade, o respeito aos ritmos de aprendizagem dos alunos, o fomento à autonomia, entre outros, que poderá fornecer subsídios para o desenvolvimento de competências docentes que levem a aprendizagens significativas.

Na perspectiva de conhecermos as especificidades das Escolas do Campo é que o artigo intitulado: Escolas/Classes Multisseriadas do Campo: reflexões para a formação docente, produzido por Natacha Eugênia Janata e Edson Marcos de Anhaia, ambos da Universidade Federal de Santa Catarina. A reflexão proposta pelos autores coloca em evidência o Projeto Escola Ativa e as necessidades de formação dos docentes que trabalham com escolas/classes multisseriadas. O texto apresenta um breve histórico sobre as formas de organização escolar em suas articulações com os períodos políticos e econômicos vivenciados no país e nos propõe pensarmos as seguintes questões: em que consistem as políticas neoliberais dos anos 1990 e como se associam à constituição da Educação do Campo? Como as formulações que envolvem a Educação do Campo podem auxiliar a problematizar a formação docente, voltadas às especificidades das escolas/classes multisseriada? Na esteira destas questões e, a partir da análise de algumas políticas neoliberais, os autores sinalizam que o fechamento e os processos de nucleação ocorridos nas escolas do campo bem como o transporte escolar como forma de atendimento aos sujeitos do campo, estão intimamente ligados ao avanço das políticas neoliberais da década de 1990. No entanto, apesar do intenso processo de nucleação, ainda é expressivo o número de escolas multisseriadas, o que aponta à necessidade de políticas específicas para a formação de professores que atendem esta forma de organização escolar. Dentre estas, destaca-se o Programa Escola Ativa que por suas características, segundo os autores, vinculou-se a propostas neoliberais e configurou-se como um contraponto ao que os movimentos sociais do campo vêm produzindo no sentido da Educação do Campo. Nesse sentido, os autores apostam que um dos princípios fundamentais para a formação de professores que atuam em classes multisseriadas corresponde a sua articulação com a Educação do Campo. O artigo encerra com uma serie de proposições para pensarmos as especificidades que demandam o processo formativo destes professores.

$\mathrm{O}$ artigo de Bruno Baronnet, do Instituto de Investigações em Educação da Universidade Veracruzana do México, cujo título: La Educación Zapatista como Base de la Autonomía en el Sureste Mexicano, aponta para as características e, principalmente para os impactos das lutas protagonizadas pelo movimento zapatista no campo educacional mexicano. Com esta intencionalidade, o autor mostra como as 
alternativas construídas, por tal movimento, se constituíram como pedagógicas e aponta para as dificuldades que as famílias zapatistas têm enfrentado na construção de propostas pedagógicas vinculadas ao projeto denominado de Educação verdadeira. Nesta perspectiva, o artigo problematiza o campo educacional no sentido de que as identidades indígenas, campesinas e zapatistas estejam contempladas no currículo escolar a fim de fortalecer o orgulho e a dignidade de um povo que foi oprimido e que busca a emancipação do neocolonialismo ainda existente. De forma geral, a reflexão proposta pelo autor se constitui como um enfrentamento às políticas públicas de educação rural que negam o contexto multicultural de desigualdade e de uma educação indígena que não é discutida e validada pelos sujeitos coletivos.

O artigo produzido por Paulo Afranio Sant'Anna e Luiz Otávio Costa Marques, da Universidade Federal dos Vales do Jequitinhonha e Mucuri, intitulado: Pibid Diversidade e a Formação de Educadores do Campo, aponta para a diversidade cultural e social existente no Brasil e sinaliza a necessidade de uma articulação entre os processos formativos e o contexto escolar que levem em consideração esta multiplicidade. Neste sentido, sinalizam a urgência de construirmos teorias e práticas pedagógicas, que tenham seu alicerce na complexidade escolar e que os licenciandos, desde o início de sua formação, tenham contato e vínculo com esta realidade. Os autores destacam o Pibid Diversidade, Programa Institucional de Bolsas de Iniciação à Docência voltado à Educação do Campo e Educação indígena, como um programa que possibilita a inserção de alunos e alunas na comunidade escolar e que fortalece a construção de práticas pedagógicas em contextos marcados pela diversidade. É nessa perspectiva, que os autores descrevem e analisam um dos subprojetos do Pibid-Diversidade da UFVJ desenvolvidos na comunidade Santa Luzia, localizada no município de Almenara em Minas Gerais. Tal subprojeto buscou articular etapas de pesquisa e ensino, tendo os resultados da primeira instrumentalizado o desenvolvimento de práticas pedagógicas vinculadas com os saberes e fazeres da comunidade local. Dentre os mais variados resultados desta experiência, os autores destacam a importância da escola para a manutenção e o fortalecimento das identidades das comunidades rurais e o protagonismo assumido pelos discentes durante seu processo formativo. O movimento de ação-reflexão-ação enfrentados, tanto pelos docentes da escola quanto pelos discentes da universidade, no confronto com a realidade da escola do campo e sua comunidade contribuiu, de forma geral, para uma interlocução criativa entre a comunidade e a escola e propiciou alterações significativas nos docentes envolvidos no que diz respeito as perspectivas de atuação no magistério, principalmente nas escolas que se encontram no meio rural.

Ainda na perspectiva de descrever e analisar práticas pedagógicas vinculadas ao processo formativo de futuros educadores do campo, o texto de Carolina dos Santos Fernandes e Geovana Mulinari Stuani, 
da Universidade Federal de Santa Catarina, discute sobre as compreensões dos estudantes em Licenciatura em Educação do Campo a respeito da temática agrotóxicos no ensino de ciências. O artigo: Agrotóxicos no Ensino de Ciências: uma pesquisa na educação do campo, segundo as autoras, sugere que a reflexão sobre o uso dos agrotóxicos, que envolve não só dimensões conceituais, sociais, econômicas e políticas, mas também de saúde pública e ambiental, permanece obscurecida nos meios de comunicação de massa e nos processos de formação docente. Ao discorrer sobre a temática analisada, as autoras discutem as relações entre Ciência, Tecnologia e Sociedade (CTS) apontando para as potencialidades pedagógicas advindas de um enfoque alicerçado nesta perspectiva para a formação de educadores do campo na Educação do Campo. Tendo como princípio metodológico a análise textual discursiva (ATD) as autoras analisaram a produção textual de 12 alunos e identificaram aproximações entre os discursos dos alunos e as reflexões propiciadas pelo enfoque CTS que questiona o chamado determinismo tecnológico, que confere a centralidade do desenvolvimento tecnológico nas mudanças sociais, a visão salvacionista da ciência e a visão tecnocrata que empodera os especialistas na tomada de decisões em detrimento da população em geral. Considerando esta temática bastante controversa, as autoras consideram que uma abordagem deste tipo no Ensino de Ciências pode ser uma potente estratégia para a constituição de sujeitos críticos, com capacidade de argumentação e poder decisório frente às demandas da vida diária.

O texto Educação do Campo: formação em ciências da natureza e o estudo da realidade, de Néli Suzana Britto e Thais Gabriella Reinert da Silva, ambas da Universidade Federal de Santa Catarina, aponta para os deslocamentos efetuados pela Educação do Campo no que diz respeito à organização curricular necessária a cursos que pretendem a formação por área de conhecimento e a organização dos tempos e espaços com a pedagogia da alternância e os desafios daí advindos. Na esteira dos princípios da Educação do Campo, as autoras buscam discutir as possíveis interlocuções que podem ser estabelecidas entre o estudo da realidade, propiciado pela pedagogia da alternância, e os tópicos ensinados na universidade/escola. Destacam a necessidade de constituirmos uma sensibilidade para apreendermos aquilo que se constitui como significativo para a comunidade, a fim de fazer emergir uma temática que conterá situações cotidianas e suas contradições, cujo estudo demandará uma abordagem interdisciplinar. Ao percorrem a história das disciplinas acadêmicas de Ensino de Ciências e Biologia (EC/B), nos períodos entre 1960/1990, em suas correlações com as tradições curriculares, o desenvolvimento científico e a produção de pesquisas no âmbito acadêmico, as autoras pontuam a guinada ocorrida no final da década de 1980, quando as ideias de Paulo Freire passam a ser referência nos debates que buscavam uma reorientação curricular. Alicerçadas em um referencial freireano, as autoras nos provocam a pensar

664 Educação \& Realidade, Porto Alegre, v. 40, n. 3, p. 659-666, jul./set. 2015. 
em uma educação problematizadora que tem na investigação temática a possibilidade de transformar as contradições vivenciadas em programas de ensino, na qual o levantamento preliminar da realidade pela escola é parâmetro para respostas para o que, por que e como olhar com a comunidade escolar e seu entorno.

A partir de uma perspectiva teórica diferenciada, o currículo escolar também passa a ser analisado no texto: Currículo e MST: conflitos de saberes e estratégias na produção de sujeitos, de Vândiner Ribeiro e Marlucy Alves Paraíso, ambas da Universidade Federal dos Vales do Jequitinhonha e Mucuri. Especificamente o artigo apresenta os conflitos que giram em torno da questão: do que deve ser ensinado nas escolas. Ou seja, dos saberes que compõe o currículo em suas interfaces com as estratégias postas a operar na constituição dos sujeitos. Nesta perspectiva, as reflexões aqui propostas nos remetem a pensar sobre as relações de poder e saber, inscritas nos currículos escolares, visto que selecionar conhecimentos coloca em funcionamento jogos de poder conflituosos, pois implica na hierarquização ou no ocultamento de saberes. De forma bastante instigante, as autoras vão apontando para os dualismos: universal versus particular; campo versus cidade; popular versus científico; certo versus errado, presentes nos currículos de uma escola de acampamento e outra de assentamento do Movimento dos Trabalhadores Rurais Sem Terra (MST). Tais dualismos e suas implicações na constituição de um modo específico de ser um sem terra são evidenciados nos saberes ecológicos, nos saberes sanitaristas e nos saberes sobre a Reforma Agrária e a demanda por uma posição de sujeito antilatifundiário desenvolvidos nos currículos investigados.

Encerrando a seção temática, o artigo de Peter Jarvis, intitulado Aprendizagem Humana: implícita e explícita, amplia a abordagem da Educação do Campo, considerando a transformação da pessoa através da aprendizagem. Argumenta que nossa consciência em relação à aprendizagem é inferior às nossas experiências de aprendizagem, sendo o conhecimento tácito a base da aprendizagem implícita. Os sujeitos da Educação do Campo têm na oralidade a principal sustentação de sua aprendizagem, dimensão essa pouco valorizada pela escola ocidental a qual privilegia a escrita e a leitura. A abordagem de Jarvis amplia as reflexões sobre a forma de aprender dos sujeitos do campo. Conforme suas reflexões, a pessoa torna-se especialista não somente absorvendo conhecimento explícito dos livros textos, mas através da experiência, de tentativas repetidas, de dispêndio de tempo e esforços, aprendendo tanto com os livros, quanto com a transgressão das regras. Jarvis valoriza o corpo, a intuição, as experiências de vida nos processos de aprendizagem.

Frente às múltiplas reflexões aqui presentes, esperamos contribuir com as discussões e práticas pedagógicas comprometidas com uma educação de qualidade para os povos que vivem no e do campo.

Educação \& Realidade, Porto Alegre, v. 40, n. 3, p. 659-666, jul./set. 2015. 


\section{Notas}

1 A Universidade Regional do Noroeste do Estado do Rio Grande do Sul (Unijuí), instituição comunitária, realizou uma das primeiras turmas nacionais do curso Pedagogia da Terra, sendo construído o projeto pedagógico junto à coordenação de Educação do MST.

2 Documento Orientador Programa Nacional de Educação do Campo - PRONACAMPO, Brasília: 2013. Disponível em: <www.portal.mec.gov.br/index. php?option=com_docman\&task $>$. Acesso em: 22 dez. 2014.

3 Na Universidade Federal do Rio Grande do Sul temos duas turmas - uma no campus litoral, em Tramandaí, e outra no campus Porto Alegre, na ênfase de Ciências da Natureza.

\section{Referências}

BAUMAN, Zygmunt. O Mal estar da Pós Modernidade. Rio de Janeiro: Zahar, 1998.

BRASIL. Ministério da Educação. Programa Nacional de Educação do Campo (PRONACAMPO). Documento Orientador, 2013. Disponível em: <www.portal. mec.gov.br/index.php?option=com_docman\&task>. Acesso em: $22 \mathrm{dez} .2014$.

CALDART, Roseli S. Elementos para a Construção do Projeto Político Pedagógico da Educação do Campo. In: PARANÁ. Secretaria de Estado da Educação. Cadernos Temáticos: educação do campo. Curitiba: SEED/PR, 2005.

CONFERÊNCIA NACIONAL: POR UMA EDUCAÇÃO BÁSICA DO CAMPO, 1, 1998, Luziânia. Anais... Luziânia: UNICEF, MST, UnB, CNBB, 1998.

PRADO, Adonia. Ruralismo Pedagógico no Brasil do Estado Novo. Estudos Sociedade e Agricultura, n. 4, jul. 1995. P. 5-27.

Claudia Glavam Duarte é doutora em Educação pela Universidade do Vale do Rio dos Sinos (2009). Atualmente é professora e coordenadora do curso de licenciatura em Educação do Campo da Universidade Federal do Rio Grande do Sul-Campus litoral. Tem experiência na área de Educação Matemática com ênfase em Ensino-Aprendizagem, atuando principalmente nos seguintes temas: Etnomatemática, Educação do Campo, saberes populares e conhecimento científico.

E-mail: claudiaglavam@hotmail.com

Simone Valdete dos Santos é doutora em Educação pela Universidade Federal do Rio Grande do Sul (2003) e doutora em Educação na modalidade sanduíche pela Universidade Federal Fluminense (2000). Atualmente é professora associada 2, vinculada ao Programa de Pós-Graduação em Educação da Universidade Federal do Rio Grande do Sul. Tem experiência na área de Educação, com ênfase em Educação de Jovens e Adultos, atuando principalmente nos seguintes temas: educação de jovens e adultos, educação profissional, formação de professores, educação profissional integrada à EJA, educação ambiental e história da educação.

E-mail: simone.valdete@ufrgs.br

666 Educação \& Realidade, Porto Alegre, v. 40, n. 3, p. 659-666, jul./set. 2015. 